\title{
CLOUD BASED DYNAMIC COURSE SELECTION FRAMEWORK USING NETWORK GRAPHS WITH TERM DIFFICULTY ESTIMATION*
}

\author{
JASEM M. ALOSTAD †
}

\begin{abstract}
The system developed in this paper uses a cloud based technology to implement and design a software as a service (SAAS) application for adaptive course selection and term difficulty estimation for a networked curriculum. The choice of courses in every term is completely in the hands of the students who enroll for a particular program in Universities. The order of courses taken in every term is ad hoc due to different factors like student interests, uncertainty about the student pass rates, frequent changes in admission policies and curriculum requirements. However, this choice of course plays a vital role in students graduating in time from the university. In this paper, we analyze student success ratios in terms of time to graduation. To illustrate the designed models, data from different colleges of the Public Authority of Applied Education and Training (PAAET), Kuwait, is used. Graph-based complex networks are used for analyzing the courses and how crucial they are. The difficulty levels of courses are estimated based on the institutional data from spring 2013 to fall 2016 and term difficulties are estimated based on the courses chosen. This work presents a robust framework which is adaptable to the courses chosen by the students and the ease of flow of students through the curriculum with the aim of improving the universitys graduation rate.
\end{abstract}

Key words: Parallel processing, Data Analytics, Cloud computing, Graph Theory, Student Success Ratio, Time to Graduation, Course Cruciality, Course Difficulty

AMS subject classifications. 68M14, 90C35

\section{Introduction.}

1.1. Background. Prediction and investigations on academic performance and the factors affecting student success and the endurance of students are topics of utmost importance in higher education [18]. Academic performance is a crucial factor in analyzing higher education levels and predicting other important job outcomes like performance in the job hired for and salary predictions [19]. The success ratio is an important metric for the students and the university. The success of a student has many definitions, varying from the grades to self-improvement [7, 8]. Most of the studies from the literature indicate student graduation in time as the most important success metric. From the perspective of the university, and especially for public universities, factors like graduation, student retention rate and time to degree are essential for the so called performance funding of the universities from the state. Generally, the final grades obtained by the student are used for analyzing the performance of a student.

The graduation rate of students depends on two factors: institutional and pre-institutional factors [11, 12]. The students perspective on the graduation rate depends on pre-institutional factors like High school performance, the demographic status of the students, socio-economic data and some of the institutional factors include the guidelines and policies of the university, tutoring, advisory arrangements and the competence of the instructors $[13,14]$. The success framework of students is shown in Fig.1.1 as discussed in [10]. Prediction and progression results are used in [17] educational data mining to analyze student performance.

In this paper we are considering the optimal course choice models for The Public Authority of Applied Education and Training (PAAET), a higher education institute in Kuwait, offering a range of programs through its various colleges across the country. There are five different colleges and two campuses differentiated gender wise, for each college. PAAET is considered as one of the largest institutes in the Middle East, taking student enrollment as a factor in the measurement. Every term approximately 40000 students are admitted to different colleges in PAAET. There are 5 different colleges, namely College of Basic Education, College of Business Studies, College of Health Sciences, College of Nursing and College of Technological Studies under PAAET. Of all the colleges, the College of Basic Education has more number of students enrolled each term. BA0106, a four year degree program of the college of Basic Education, PAAET, is considered for further processing, analysis and discussion in this paper.

\footnotetext{
*This work was supported by The Public Authority of Applied Education and Training, Kuwait.

†College of Basic Education, The Public Authority of Applied Education and Training (PAAET), Kuwait,(jm.alostad@paaet.edu.kw).
} 


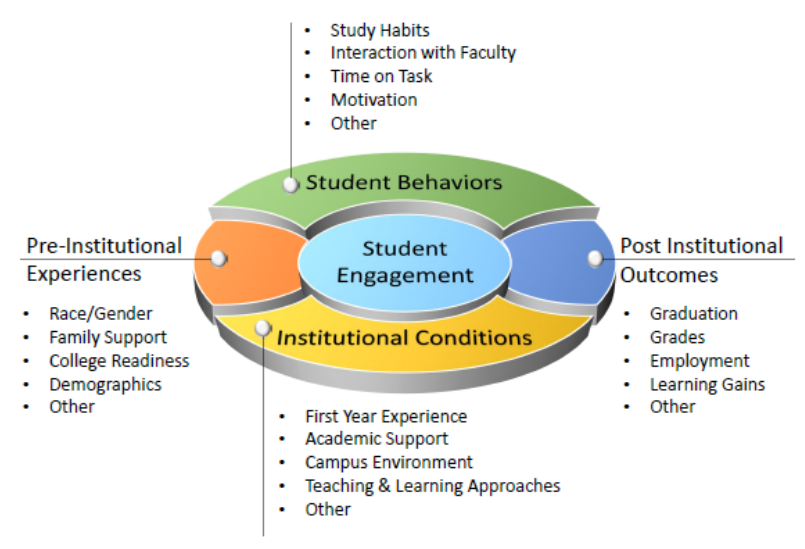

FIG. 1.1. Student success framework.

1.2. Problem Statement. Student graduation rate is one of the most important metric in evaluating the rank of a College or University. Universities where the success ratio is large, has largest enrollments in years to come. E-Advisor is a web based application providing online guidance to the students of PAAET. Here guidelines are given in the direction of finding appropriate disciplines so they can succeed by graduating in-time. The e-advisor system provides the detailed information of the different colleges in PAAET, their major courses, the success rate in each of the course in the previous years and the rules and regulations of the Authority. The current system lacks options for guiding student about the subjects that has to be chosen in future semesters. Hence, for the objective of increasing the Graduation rate of the student, choice of courses in every term is taken into consideration in this work. The proposed solution acts as an advising system for the students. This solution helps students who are below average and who are unaware of being expelled from college for reaching the maximum allowed semesters in their period of graduation. They system alerts the students as early in his/her 3 rd semester about his delay in graduation and time to graduation.

1.3. Proposed Solution. A critical institutional factor that is often glossed over is the order of course choices every term i.e. the structure of the curriculum, which is linked with the program which a student has selected. This is one of the most relevant perspectives in understanding the academic performance of a student. Hence, in this paper we analyze the course choices in every term and identify the most crucial courses in the curriculum. The key point is failure in such crucial courses or if the courses are not taken according to schedule this will directly lead to delay in graduation. This analysis is carried out program wise. In this process we developed an adaptable framework which is used to guide the student on choosing courses every term so that he is not delayed in graduation.

Contributions: In this paper the problem of student success ratio is addressed in terms of his/her graduation in-time from the university. The proposed algorithm incorporates the following unique features

1. A network graph for the entire courses in a particular program is constructed for the algorithm implementation.

2. Course prerequisites, co requisites and level of the courses are taken into consideration.

3. An important feature for student success; choice of courses in every allowed term by students in order to identify their time to graduation is considered. As an advisory system, our algorithm gives an optimal set of courses for a student for a term in order to graduate in time.

4. A dynamic course selection algorithm is developed which displays the optimal choice and allows a student to decide the courses on his own. Depending on the courses chosen; the algorithm dynamically recomputes the optimal choice of courses from the next term and an alert is generated if the student is expected to exceed the number of allowed terms.

5. The difficulty of every course in the program is identified using the institutional data from the years 
2013 to 2016.

6. With the calculated course difficulty, term difficulty is computed and future term difficulty is also predicted with the current selection of courses.

Organization: The rest of the paper is organized as follows. Section 2 gives a brief review of the literature considering the work done earlier in this field. In section 3 the proposed adaptive course selection framework is presented in detail, considering the static and dynamic selections. Section 4 presents details about the difficulty analysis of every course in the chosen program. Section 5 discusses the numerical results obtained with the sample data and Section 6 concludes the work.

2. Related Works. A student performance analysis system presented in [1] uses students' grades to classify students into different clusters. The performance of a student on a particular course is analyzed and predicted using data mining techniques. A case study on the Educational data mining techniques is presented in [2], where classification based data mining algorithms are presented for analyzing the student performance. Similarly in an exhaustive study in the field of educational data mining [3], the prediction algorithms used for student performance analysis and their comparison is presented.

Abeer and Elaraby [4] used the demographic information about students, including their behaviour and activities, with rules for classification and predicted the performance of students. The approximate grades of the students are predicted, which helped in improving the student performance on future courses.

An association rule based performance prediction and improvement in higher education is proposed in [6]. The work presented in [5] is based on knowledge mining from the educational data using a decision tree and identifying the students with low performance ranges and it suggests improvements in their learning methodology.

In [15] different metrics for measuring student success are analyzed. The five most important metrics included in the discussion are: retention rates, graduation rates, time to completion, academic performance, and tracking educational goals. The graduation rate and the retention rate are closely related and the factors affecting both the metrics are almost the same. The most important factor to be considered in these two metrics is the unpredictability in students' paths. A prediction model for identifying the social, economic and psychological factors a student is facing in his adolescence is analyzed in [16]. The model takes data balancing, dimensionality reduction, discretization and normalization to pre process the data and predictor construction.

In all the work proposed in the literature in the direction of analysis of student success or performance analysis recent data mining techniques have been used to analyze the performance of the students and identify good or bad performance, enabling the teacher and the student himself to explore different ways to improve performance in future terms. We recognize an important factor in student success as the courses taken during his period of study. Difficulty analysis is done for different courses in [22], where different data such as high school GPA, ICT scores, demographic data and the grades obtained by the students in the previous years are taken into consideration. The institutional data plays a major role in deciding the difficulty of the courses conducted in the university. Hence, in this work we build upon this to identify the static and dynamic term difficulty as a warning or information for students, providing awareness about the level of his course. Curriculum design patterns and applications are explained in detail in [20,21], which is the basis of the work presented in this paper. The difficulty level and how crucial courses are considered to be should be known before choosing a course. Hence, in this work we present a framework for providing an optimal choice of courses for a particular term for a student so that the success rate of the student increases, enabling a high graduation rate from the university.

3. Adaptive Course Selection Framework. The proposed course selection framework is explained in detail in what follows. The network construction of courses in the curriculum of a program is described first and the algorithm for deciding the optimal course choice is discussed later.

3.1. Course Network Construction. As a measure of a students success, graduating in time from the university is considered as an important institutional factor. For a student to graduate in time the requirement is completion of the courses and earning the required credits. The order of course choice plays an important role in time to graduation as the courses in the curriculum are sometimes not dependent but some of the courses has pre-requisites which have to be completed before taking them up. Hence, in this paper the curriculum 
associated with a particular degree program is taken and the choice of courses in different terms is identified using the course selection algorithm. Due to the nature of course networks, graph theory and complex network analysis is used to find out the most crucial courses in the curriculum mathematically. This calculation of how crucial a course is can guide the student in deciding when to choose a particular course in order to avoid delay in graduation.

The curriculum graphs are constructed using graph theory. Here the courses in the curriculum are represented as the nodes and two nodes are connected if the course has a direct prerequisite. Hence, the course network is represented as an $N x N$ adjacency matrix $\mathrm{M}$, where $\mathrm{N}$ is the number of courses in a program. If there is a vertex between two nodes the corresponding entry in the adjacency matrix $M_{i j}=1,0$ otherwise .

We define two properties, the Delay factor and blocking factor for each course. The Delay and Blocking factor is 0 for courses that are independent, i.e courses without any prerequisites. Hence, for the courses with prerequisites the length of the longest path from a node to its leaf node is the delay factor $D f_{i}$. The delay factor identifies courses that drive a student to being at risk if it is not finished on time. Connectivity of a node is considered in calculating the blocking factor of the node $B f_{i}$. The Blocking factor identifies the courses that are prerequisites for a large number of courses. If such a course is not completed at the right time a student may be blocked from the follow-on courses, which means negative progress towards graduation. The total number of nodes connected to a particular node gives $B f_{i}$ of a node. $B f_{i}$ is defined by equation 3.1:

$$
B f_{i}=\sum_{j} n_{i j}
$$

where $n_{i j}=1$ if there is a path from $i$ to $j, 0$ otherwise. Cruciality of a node is calculated as the sum of the blocking factor and the delay factor. Cruciality $C_{i}$ is given in equation 3.2 :

$$
C_{i}=B f_{i}+D f_{i}
$$

Hence cruciality factor of a course plays a vital role in deciding when to take a particular course. Since delay and blocking both are taken into consideration, a high crucial course implies that the course has to be given preference and taken in appropriate time failing which results in delay in graduation.

3.2. Static Course Preference Algorithm. The Algorithm for course selection is given in Fig.3.1. Let Cr be the number of courses in the curriculum, $\mathrm{T}$ be the number of terms, assign the credit points to all the

\section{Algorithm 1 Static Course Preference}

Let $\mathrm{N}$ be number of courses in each term

Initialize $t=1$

while $\mathrm{Cr}$ is not empty and $t<T$ do

1. Calculate the cruciality of the courses listed in the curriculum

2. Sort the list of courses in ascending order of course levels and descending order of the cruciality factor

3. Select the first $\mathrm{N}$ courses from the list so as to satisfy the limits in the sum of credits that can be registered.

4. Select the courses such that there are no prerequisites.

5. Check if any of the selected coursehas co-requisites. if true the co-requisites and its corresponding prerequisites if any has to be processed first.

6. These courses will fill term .

7. Remove the selected courses

from $\mathrm{Cr}$ and $\mathrm{M}$

end while

8. $t=t+1$

FIG. 3.1. Course Preference algorithm 


\section{Algorithm 2 Dynamic Course Preference}

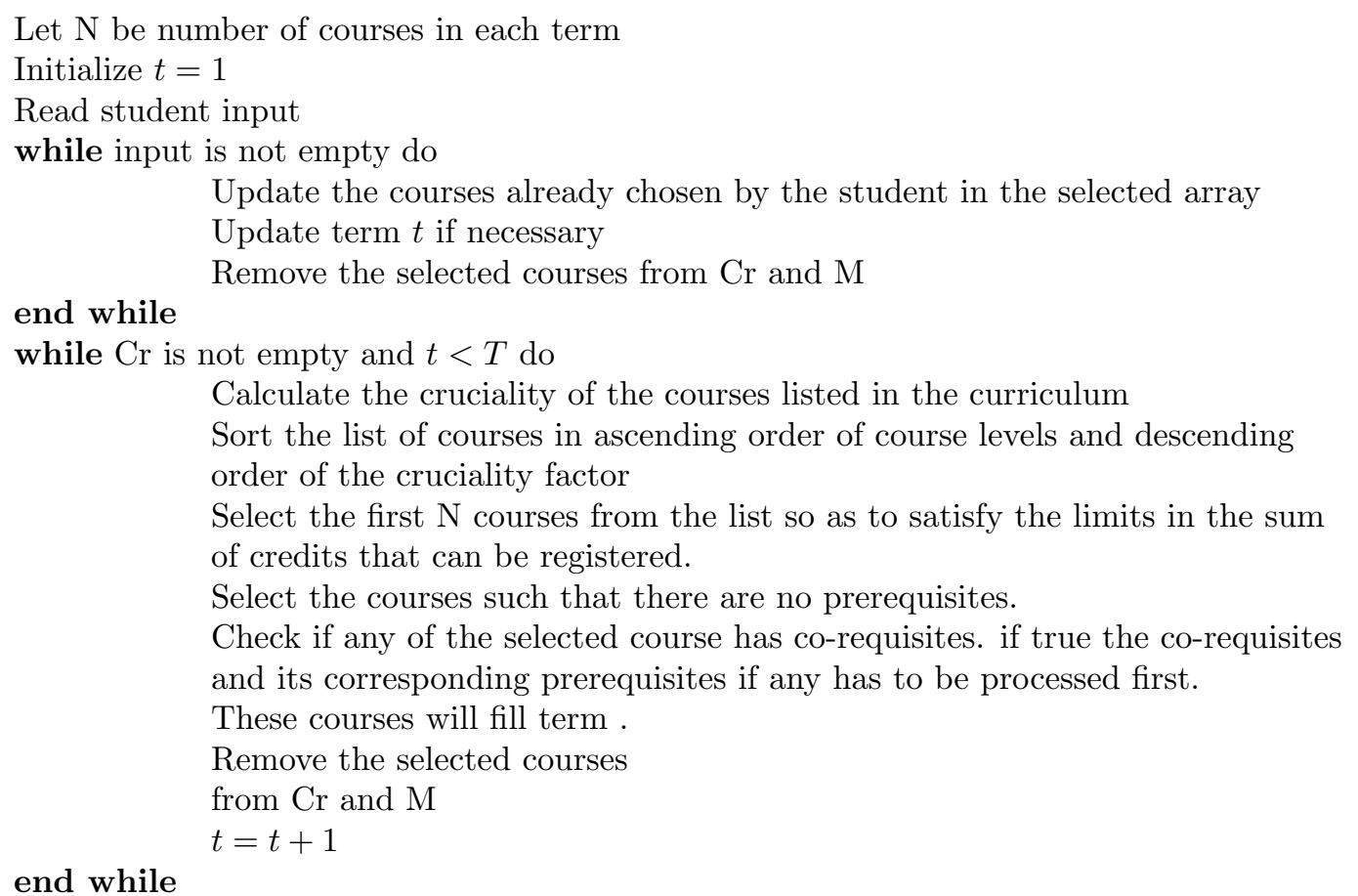

FIG. 3.2. Dynamic Course Preference algorithm

terms as mentioned, and let $\mathrm{M}$ be the adjacency matrix representing the course and the prerequisite relation. The algorithm generates an ordered list of courses term-wise for the student, so that he can graduate in time within the allowed terms.

3.3. Dynamic Course Preference algorithm. The Dynamic course preference algorithm allows a student to choose a course on his own (which may or may not be from the output of the static algorithm), and for the rest of the terms the ordered courses list is displayed to the student. The number of terms required to graduate with the current choice of courses is also displayed in the output of the algorithm. The algorithm is shown in Fig. 3.2.

4. Course Difficulty: Institutional Data Analysis. Institutional Data for 8 terms from spring 2013 to fall 2016 are analyzed to identify the difficulty of courses. The difficulty estimations are done based on the previous grades. Mean and standard deviations are calculated for the grade distributions for all the courses for each of the 8 terms. Some of the courses are not taught in some terms and, hence, the means of the courses for those particular terms are not available. The rank for each course in each term is calculated and as a sample the ranks of 25 courses are shown in Table 4.1. The ranks indicate there is a considerable amount of variation in grade distribution in every term.

In order to ensure stability of course difficulty over time, mean of the grade values are ranked. In spite of ranking the mean of the grade values there are difference in some mean grades because not all the courses are taught in all the semesters, it depends on the choice of the students. To analyze these variations further, correlation among the 8 terms are calculated using pearson's $R$ method. On examining the correlation coefficients supports the general idea that the grade distributions are consistent across several semesters. The calculated correlations are plotted in the correlation plot shown in Fig.4.1. The correlation matrix is shown table 4.2. The minimum correlation exists between the terms Spring2016 and Fall 2016, on examining the mean grade values of these terms reveals that several courses had their extreme values in these semesters. The correlation graph 
TABLE 4.1

Rank of Courses (mean grades) in Various Terms

\begin{tabular}{|c|c|c|c|c|c|c|c|c|}
\hline Courses & S13 & F13 & S14 & F14 & S15 & F15 & S16 & F16 \\
\hline X101.102 & 5 & 6 & 6 & 29 & 47 & 9 & 1 & NA \\
\hline X102.101 & 3 & 3 & 2 & 1 & 6 & 2 & 4 & 13 \\
\hline X102.102 & 4 & 5 & 4 & 6 & 10 & 3 & 8 & 7 \\
\hline X103.105 & 1 & 1 & 3 & 4 & 5 & 5 & 2 & 3 \\
\hline X103.115 & 2 & 2 & 1 & 2 & 3 & 1 & 3 & 4 \\
\hline X106.101 & 9 & 13 & 11 & 12 & 14 & 4 & 13 & 11 \\
\hline X106.104 & 10 & 4 & 5 & 11 & 7 & 7 & 10 & 8 \\
\hline X107.104 & 55 & 10 & 48 & 25 & 54 & 51 & 40 & 45 \\
\hline X107.121 & 54 & 54 & 52 & 50 & 46 & 46 & 38 & 46 \\
\hline X107.124 & 39 & 35 & 39 & 36 & 20 & 32 & 35 & 38 \\
\hline X107.131 & 42 & 41 & 50 & 47 & 31 & 34 & 31 & 20 \\
\hline X107.134 & 51 & 16 & 18 & 22 & 8 & 37 & 22 & 26 \\
\hline X107.154 & 26 & 32 & 35 & 32 & 18 & 8 & 42 & 12 \\
\hline X107.161 & 45 & 33 & 43 & 31 & 36 & 36 & 30 & 47 \\
\hline X107.171 & 52 & 47 & 45 & 33 & 41 & 40 & 29 & 35 \\
\hline X107.194 & 41 & 27 & 26 & 35 & 13 & 21 & 5 & 32 \\
\hline X107.214 & 33 & 38 & 46 & 45 & 23 & 30 & 39 & 17 \\
\hline X107.244 & 28 & 34 & 41 & 38 & 19 & 24 & 25 & 25 \\
\hline X107.251 & 48 & 48 & 54 & 26 & 21 & 22 & 37 & 30 \\
\hline X107.254 & 35 & 36 & 22 & 43 & 22 & 42 & 6 & 48 \\
\hline X107.264 & 50 & 42 & 21 & 42 & 26 & 23 & 9 & 44 \\
\hline X107.331 & 53 & 51 & 53 & 51 & 51 & 49 & 48 & 31 \\
\hline X107.341 & 49 & 53 & 42 & 46 & 43 & 33 & 32 & 43 \\
\hline X107.342 & 43 & 40 & 40 & 49 & 37 & 48 & 45 & 40 \\
\hline X107.372 & 44 & 52 & 44 & 18 & 27 & 20 & 43 & 23 \\
\hline
\end{tabular}

TABLE 4.2

Correlation of mean grades for 8 terms

\begin{tabular}{|c|c|c|c|c|c|c|c|c|}
\hline & S13 & F13 & S14 & F14 & S15 & F15 & S16 & F16 \\
\hline S13 & 1.0000000 & 0.77334600 & 0.86108600 & 0.7729660 & 0.6197429 & 0.7623634 & 0.6105081 & 0.6783107 \\
\hline F13 & 0.7733460 & 1.00000000 & 0.85515533 & 0.8075693 & 0.6784647 & 0.7075601 & 0.6590922 & 0.6438203 \\
\hline S14 & 0.8610860 & 0.85515533 & 1.00000000 & 0.8437116 & 0.7005898 & 0.7777775 & 0.6910246 & 0.6487445 \\
\hline F14 & 0.7729660 & 0.80756928 & 0.84371157 & 1.0000000 & 0.6835913 & 0.8127427 & 0.6042601 & 0.7371457 \\
\hline S15 & 0.6197429 & 0.67846468 & 0.70058981 & 0.6835913 & 1.0000000 & 0.6993695 & 0.7079145 & 0.5426127 \\
\hline F15 & 0.7623634 & 0.70756014 & 0.77777746 & 0.8127427 & 0.6993695 & 1.0000000 & 0.5991665 & 0.7315858 \\
\hline S16 & 0.6105081 & 0.65909216 & 0.69102459 & 0.6042601 & 0.7079145 & 0.5991665 & 1.0000000 & 0.5144824 \\
\hline F16 & 0.6783107 & 0.64382030 & 0.64874449 & 0.7371457 & 0.5426127 & 0.7315858 & 0.5144824 & 1.0000000 \\
\hline
\end{tabular}

indicates that there is no correlation in the opposite direction. Deviations from normality are also identified using the Shapiro-Wilk's test. The sample normality plots for fall 2014 and spring 2016 shown in Fig.4.2 show no traces of lack of normality. The $\mathrm{p}$ values range from 0.1895 to 0.9958 .

\section{Numerical Results and Discussions.}

5.1. Static Course Choices. To showcase the above mentioned process we have selected the courses of the BA0106 program of the College of Basic Education, PAAET. There are 90 courses in total and these are categorized as mandatory courses for the Major, Elective courses, and General courses. Of the three categories the student has to choose courses totaling 130 credits in 4 years to graduate. The number of credits a student can register for a term is restricted to 18 in fall and spring and 7 in summer. The summer terms are optional for the students. The entire set of courses in the program is represented as the network shown in Fig.5.1. The nodes in the network represent the courses. Courses are named as a combination of the department id and the course id. The courses without any prerequisites are represented as nodes without any edges and the courses connected by prerequisites have edges between them.

The cruciality factor is calculated for the courses in the program according to equation 3.1. The most 


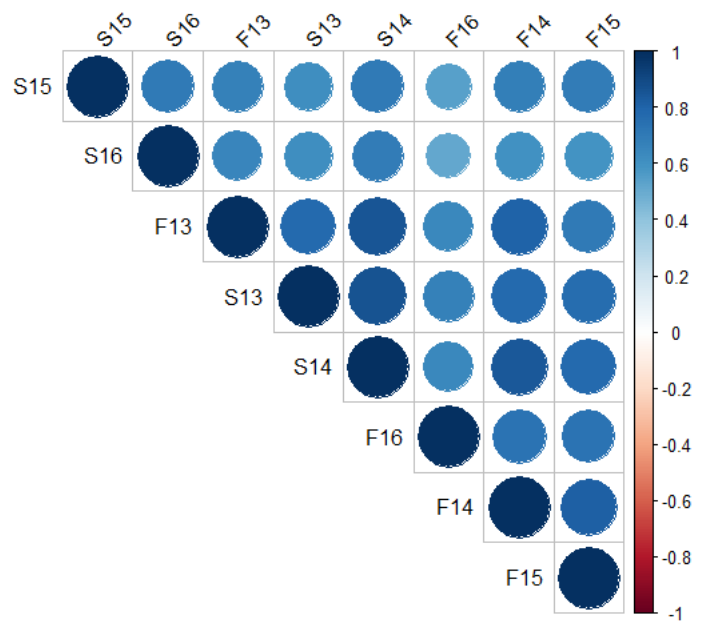

FIG. 4.1. Correlation among the 8 terms

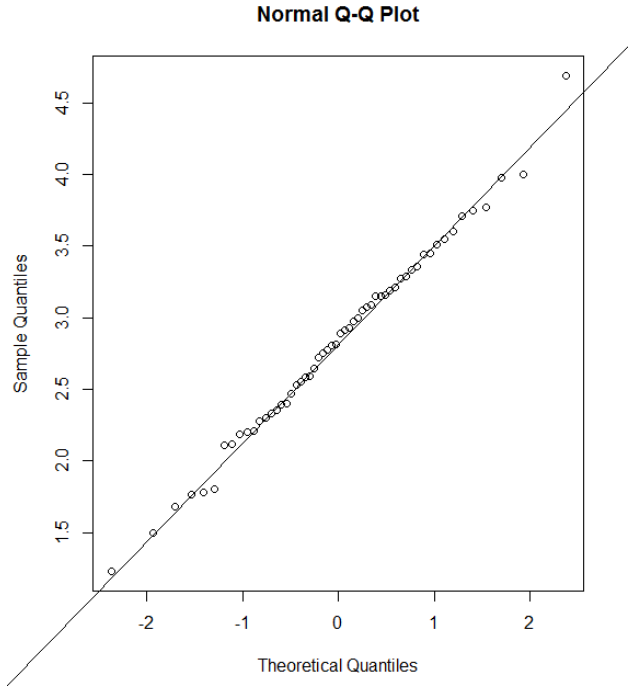

(a) Case I

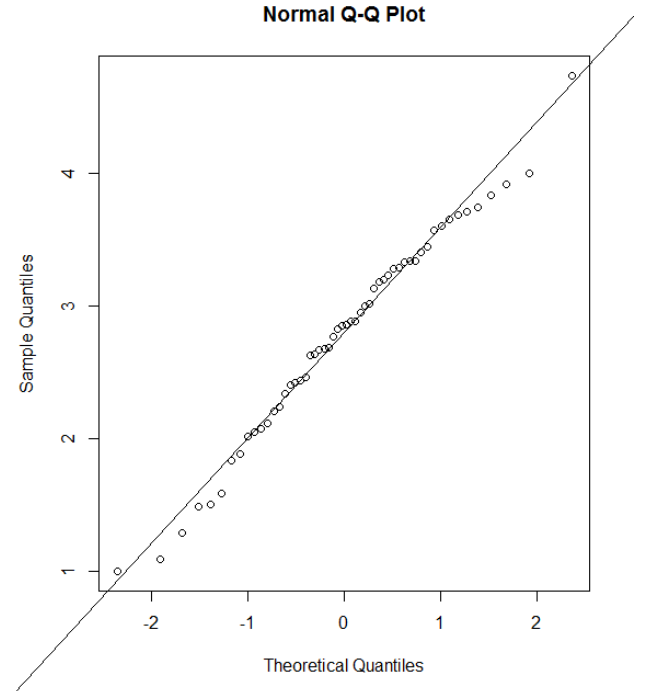

(b) Case II

FIG. 4.2. Sample normality plots for Fall 2014 and Spring 2016

crucial 10 courses are shown in Table 5.1.

The static course preference algorithm is executed on the network constructed. The different courses that a student has to choose in order to graduate in time are the output generated from the algorithm. These lists of courses are shown in Table 5.2. The co-requisites and prerequisites are handled optimally and the course levels are also taken into consideration. The total number of credits earned is 130 .

5.2. Adaptive course choices. The actual choice of courses is in the hands of the students. Hence, we have also presented a dynamic version of the algorithm which initially displays the optimal choice of courses and reads the input file containing the actual courses chosen by the student and, based on the courses chosen; the set of optimal choices for the upcoming terms is displayed to the student. The algorithm also displays the number of terms a student will actually need for graduation with his current choice of courses. Based on the output the student may choose to take one or more summer terms as per his requirements. As an illustration 


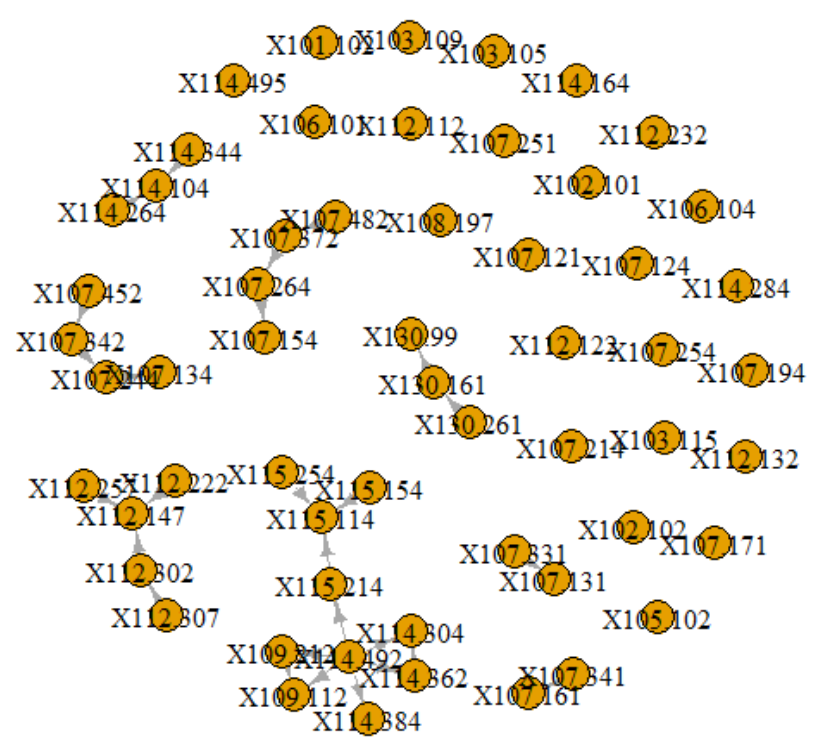

FIG. 5.1. Course Network Structure of courses and Prerequisite courses

TABLE 5.1

10 Most crucial courses in the Curriculum

\begin{tabular}{|c|c|c|c|}
\hline Course & Connectivity & Delay & Cruciality C \\
\hline X114.492 & 6 & 3 & 9 \\
\hline X115.114 & 5 & 3 & 81 \\
\hline X109.112 & 2 & 4 & 6 \\
\hline X109.212 & 2 & 4 & 6 \\
\hline X114.304 & 2 & 4 & 6 \\
\hline X114.362 & 2 & 4 & 6 \\
\hline X114.384 & 1 & 4 & 5 \\
\hline X115.154 & 1 & 4 & 5 \\
\hline X115.254 & 1 & 4 & 5 \\
\hline X115.424 & 1 & 4 & 5 \\
\hline
\end{tabular}

of the dynamic course selection algorithm, for the above mentioned program BA0106, the courses chosen by a student as shown in Table 5.3 is given as the input. For the given input the choice of courses to be chosen is given in Table 5.4. It can be observed from Table 5.4 that the first two term data is given from the actual courses chosen by the student and for the rest of the terms the courses to be chosen are displayed in Table 5.4. The number of terms in Table 5.4 is given as 9, hence, the student is expected to exceed one term over the allotted number of terms. The student can plan for a summer term in order to graduate in time.

Fig. 5.2 shows the dynamic course network that adapts to the courses chosen by the student. The 8 subfigures of Fig.5.2 present the structure of the network after choosing the courses. It represents the remaining courses in the curriculum of the program after every term. It can be observed from the figure that the remaining courses in Fig.5.2.(h) are the courses chosen in the $9^{\text {th }}$ term by the student as shown in Table 5.4. It can also be inferred from Table 5.4, that the course levels are not maintained in the dynamic selection. The reason is the input decided by the student is random without considering the course levels, with the random input the cruciality, co-requisites and prerequisites are considered since the input does not follow the level.

5.3. Difficulty Estimation for Courses. The course difficulties are estimated based on the institutional data, i.e the grade distributions. The careful examination of the correlation coefficients supports the general perception that the distribution of grades is highly consistent across semesters. The Shapiro-Wilk's test and the 
TABLE 5.2

Term wise courses

\begin{tabular}{|c|c|c|c|c|c|c|c|c|}
\hline Term 1 & X130.99 & X102.101 & X106.101 & X102.102 & X101.102 & X114.103 & X114.104 & X106.104 \\
\hline Term 2 & X107.104 & X103.105 & X109.112 & X112.112 & X115.114 & X103.115 & X107.121 & \\
\hline Term 3 & X112.122 & X107.124 & X107.131 & X112.132 & X107.134 & X112.147 & X115.154 & X107.154 \\
\hline Term 4 & X130.161 & X107.161 & X114.164 & X107.171 & X107.194 & X108.197 & X109.212 & X115.214 \\
\hline Term 5 & X107.214 & X112.222 & X112.232 & X107.244 & X107.251 & X115.254 & X107.254 & X112.257 \\
\hline Term 6 & X130.261 & X107.264 & X114.284 & X112.302 & X114.304 & X107.331 & X107.341 & \\
\hline Term 7 & X112.307 & X107.342 & X114.344 & X114.362 & X107.372 & X114.384 & X114.464 & \\
\hline Term 8 & X114.492 & X114.495 & X107.482 & X107.452 & & & & \\
\hline
\end{tabular}

TABLE 5.3

Student Course Choice input

\begin{tabular}{|c|c|c|}
\hline Term & Dept_code & Course_Number \\
\hline 1 & 114 & 384 \\
\hline 1 & 103 & 105 \\
\hline 1 & 115 & 114 \\
\hline 2 & 114 & 284 \\
\hline 2 & 101 & 102 \\
\hline 2 & 114 & 304 \\
\hline 2 & 108 & 197 \\
\hline
\end{tabular}

Pearson's coefficients determine the stability of average grades. It appears to be a reasonable assertion that the grade distribution of individual courses does not change considerably from term to term. To be certain some variations indeed do occur in a minimal number of courses.

Nevertheless, the average grades appear to be stable enough to be used for estimating course difficulties. Hence, the eight term grade distributions are combined into one set of 57 grade distributions. Hence, average grades and their standard deviation are calculated, a sample of the first 25 courses is shown in Table 5.5 and these means are ranked in ascending order to identify the most difficult course.

The difficulty levels of the courses are represented in a heat map in Fig. 5.3. The colors vary from dark red to yellow for courses that are more difficult to easy.

With these course difficulty levels we also calculate the term difficulty by averaging the difficulty level of courses chosen for a particular term. Term difficulty is calculated both for the static course choices as in Fig. 5.4.(a) and dynamic course choices as in Fig. 5.4.(b). In the dynamic algorithm the term difficulty of the future terms is also predicted. This is given as advice to the student so that the courses can be chosen according to his convenience.

In another direction, this dynamic course preference algorithm can be used for identifying the students who will not graduate with the maximum allowed terms for graduation. Every program has the designated number of terms for a student to graduate in-time from the university. There is also a maximum allowed term for graduation beyond which a student can never graduate. Such a category of student who is anticipated not to graduate is identified early by the proposed algorithm, so that the management can decide upon such students in their early terms instead of allowing them for the maximum terms and terminating them from the university. On the other hand, a student is also given an opportunity to decide on his future in his early college life.

The cruciality analysis for different courses can be expanded department-wise and college-wise in order to identify the department with more crucial courses and the college with the most crucial departments. This data can be used further in allotting grade ranges for different subjects. The future direction of this work is allocating grade ranges for subjects within the curriculum. The grade ranges may vary based on the cruciality of the course. Less crucial courses have different ranges of values for grades compared to more crucial courses. The outcome GPA, which counts in factors like employment and higher education, will there for be fair to all students, be it a student who graduated studying less crucial courses or more crucial courses.

6. Conclusion and future enhancement. In this paper, network analysis and graph theory have been used to propose a framework to understand the structure of University courses by calculating the cruciality factor. Using this framework, the course selection algorithm shows the optimal choice of courses to be selected 
TABLE 5.4

Student Course Choice input

\begin{tabular}{|c|c|c|c|c|c|c|c|c|}
\hline 1 & $\mathrm{X} 114.384$ & $\mathrm{X} 103.105$ & $\mathrm{X} 115.114$ & & & & & \\
\hline 2 & $\mathrm{X} 114.284$ & $\mathrm{X} 101.102$ & $\mathrm{X} 114.304$ & $\mathrm{X} 108.197$ & & & & \\
\hline 3 & $\mathrm{X} 109.112$ & $\mathrm{X} 114.362$ & $\mathrm{X} 112.147$ & $\mathrm{X} 115.154$ & $\mathrm{X} 115.254$ & $\mathrm{X} 107.134$ & $\mathrm{X} 107.154$ & $\mathrm{X} 114.104$ \\
\hline 4 & $\mathrm{X} 109.212$ & $\mathrm{X} 107.244$ & $\mathrm{X} 107.264$ & $\mathrm{X} 115.214$ & $\mathrm{X} 112.222$ & $\mathrm{X} 112.257$ & $\mathrm{X} 112.302$ & $\mathrm{X} 114.344$ \\
\hline 5 & $\mathrm{X} 114.492$ & $\mathrm{X} 114.495$ & $\mathrm{X} 107.372$ & $\mathrm{X} 107.342$ & $\mathrm{X} 112.307$ & $\mathrm{NA}$ & $\mathrm{NA}$ & $\mathrm{NA}$ \\
\hline 6 & $\mathrm{X} 107.452$ & $\mathrm{X} 107.482$ & $\mathrm{X} 130.99$ & $\mathrm{X} 107.121$ & $\mathrm{X} 107.131$ & $\mathrm{X} 107.161$ & $\mathrm{X} 107.171$ & $\mathrm{X} 107.251$ \\
\hline 7 & $\mathrm{X} 130.161$ & $\mathrm{X} 112.112$ & $\mathrm{X} 107.331$ & $\mathrm{X} 107.341$ & $\mathrm{X} 107.124$ & $\mathrm{X} 107.194$ & $\mathrm{X} 107.214$ & $\mathrm{X} 107.254$ \\
\hline 8 & $\mathrm{X} 130.261$ & $\mathrm{X} 102.102$ & $\mathrm{X} 106.104$ & $\mathrm{X} 103.115$ & $\mathrm{X} 112.132$ & $\mathrm{X} 114.164$ & $\mathrm{X} 112.232$ & NA \\
\hline 9 & $\mathrm{X} 102.101$ & $\mathrm{X} 106.101$ & $\mathrm{X} 114.264$ & $\mathrm{X} 105.102$ & $\mathrm{X} 112.122$ & $\mathrm{X} 103.109$ & $\mathrm{NA}$ & NA \\
\hline
\end{tabular}

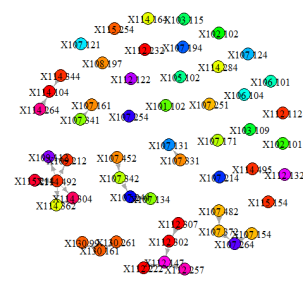

(a) Case I

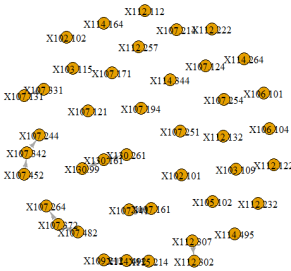

(c) Case III

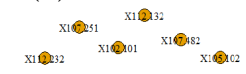

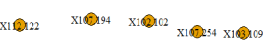

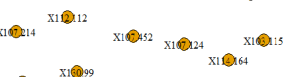

$x 1024+21$

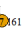

(e) Case V

x1खน15

x1222

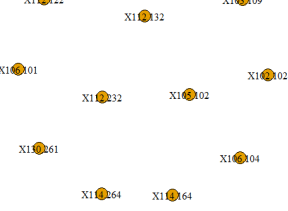

(g) Case VII

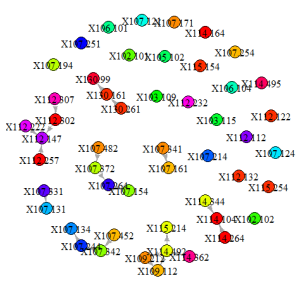

(b) Case II

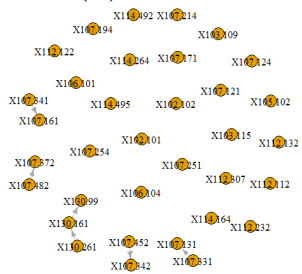

(d) Case IV

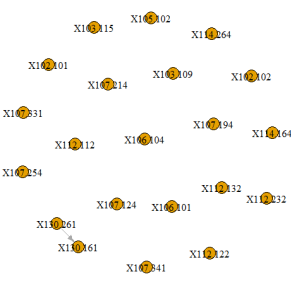

(f) Case VI

x13. 109

x1122

h) Case VIII

FIG. 5.2. Structure of the course network after removing courses every term

by a student in order to graduate in time. This choice of courses keeps track of his time to graduation. The dynamic course preference algorithm takes the student decision and based on the decision his courses and number of terms required to graduation is presented which enables the student to plan for extra courses in the upcoming terms and supports him in deciding on the summer term. The framework can be extended to trace the progress of the students based on the grades obtained and the number of courses chosen along with the cruciality factor to have a positive impact on the graduation rates. The difficulty analysis helps in maintaining 
TABLE 5.5

Mean Grades indicating the course difficulty

\begin{tabular}{|c|c|c|}
\hline Courses & Mean grades & SD \\
\hline X103.115 & 1.287398716 & 0.222689073 \\
\hline X103.105 & 1.394775842 & 0.276204191 \\
\hline X102.101 & 1.555222426 & 0.356798592 \\
\hline X102.102 & 1.819692206 & 0.203383015 \\
\hline X106.104 & 2.016552526 & 0.210480467 \\
\hline X114.344 & 2.164735106 & 0.51446792 \\
\hline X101.102 & 2.206264413 & 0.69981009 \\
\hline X106.101 & 2.235902851 & 0.249309948 \\
\hline X114.284 & 2.30080383 & 0.502985535 \\
\hline X115.214 & 2.328451714 & 0.595838926 \\
\hline X109.112 & 2.410101831 & 0.316662409 \\
\hline X114.104 & 2.449580312 & 0.41757027 \\
\hline X114.164 & 2.506503807 & 0.791445629 \\
\hline X114.304 & 2.524069967 & 0.82630547 \\
\hline X112.147 & 2.547242765 & 0.341405059 \\
\hline X114.384 & 2.594689678 & 0.654464115 \\
\hline X115.254 & 2.623985029 & 0.672616448 \\
\hline X115.154 & 2.634053128 & 0.324480842 \\
\hline X130.261 & 2.636714159 & 0.318058341 \\
\hline X112.232 & 2.654884638 & 0.416786992 \\
\hline X107.194 & 2.704502393 & 0.590925762 \\
\hline X115.114 & 2.716668919 & 0.314458112 \\
\hline X130.161 & 2.764785793 & 0.561615129 \\
\hline X112.112 & 2.768196564 & 0.4150545 \\
\hline X107.154 & 2.771499036 & 0.468601654 \\
\hline & \multicolumn{2}{|c}{}
\end{tabular}
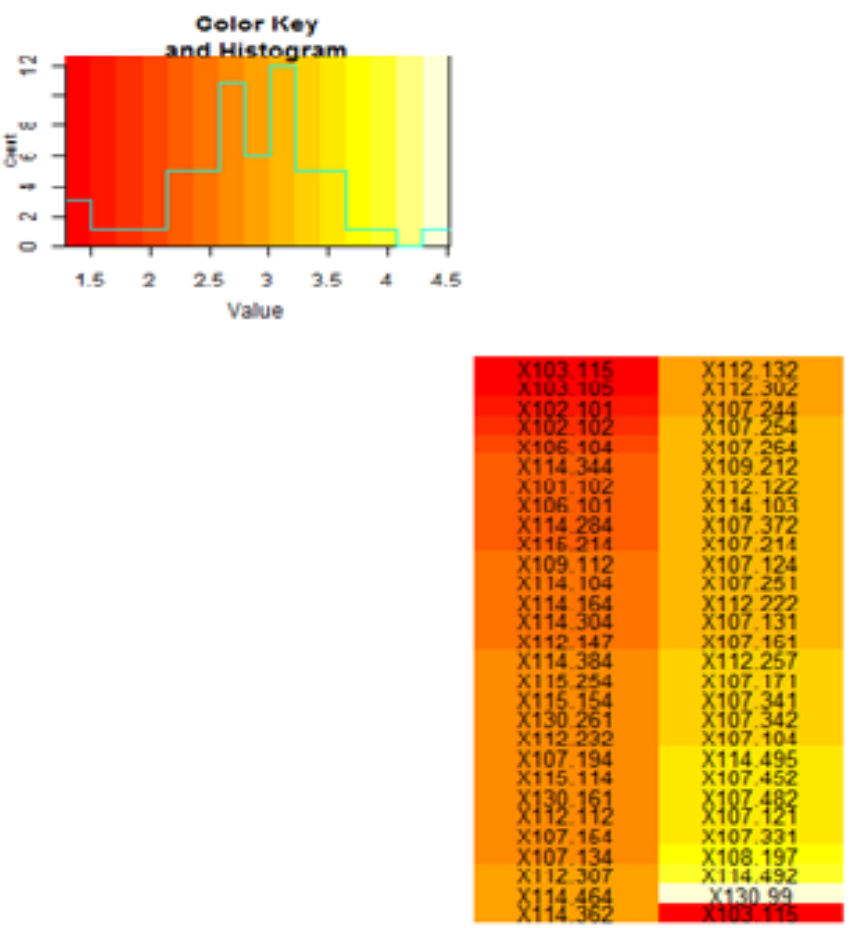

FIG. 5.3. Difficulty level of all courses in the network. 

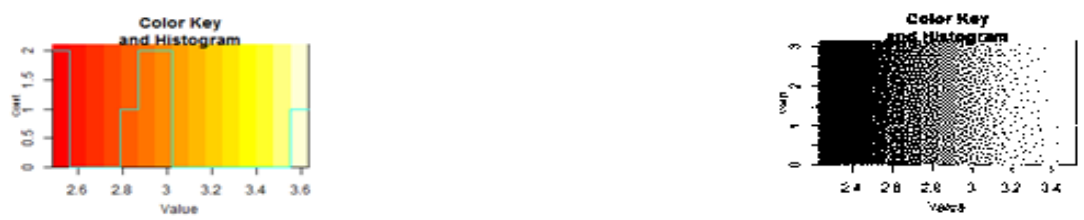

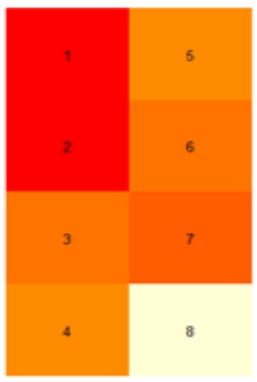

(a) Case I

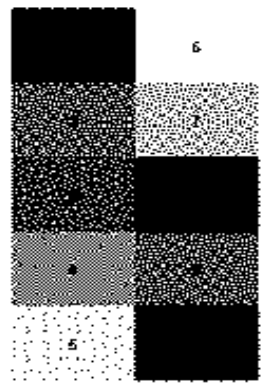

(b) Case II

FIG. 5.4. Difficulty level of terms (a) static term difficulty (b) Dynamic term difficulty

a medium hard semester for the student. The student can decide for himself the hardness of a term based on his personal conditions. The entire system is provided as software as service application in the cloud and enable student to register for course from any where irrespective of his location.

\section{REFERENCES}

[1] C. L. Sa, D. H. B. Abang Ibrahim, E. Dahliana Hossain, M. Bin Hossin, "Student performance analysis system (SPAS), Information and Communication Technology for The Muslim World (ICT4M) 2014 The 5th International Conference on, pp. 1-6, 2014.

[2] Kundariya, Daxa and Vaseem, ,A Case Study For Student Performance Analysis Based On Educational Data Mining (Edm), (2016), 10.5281/zenodo.168107.

[3] Pooja Thakar, Anil Mehta, Manisha ,Performance Analysis and Prediction in Educational Data Mining: A Research Travelogue, International Journal of Computer Applications (0975 8887) Volume 110 No. 15, January 2015

[4] Ahmed, A.B.E.D. and Elaraby, I.S.,Data Mining: A prediction for Students Performance Using Classification Method, World Journal of Computer Application and Technology, 2014 2(2), pp.43-47.

[5] Al-Radaideh, Q., Al-Shawakfa, E. and Al-NajJar, M., Mining Student Data Using Decision Trees, The 2006 International Arab Conference on Information Technology(ACIT2006),2006, Conference Proceedings.

[6] Zhu, Li, Yanli Li, and Xiang Li,Research on EarlyWarning Model of Students Academic Records Based on Association Rules, Computer Science and Information Engineering, 2009 WRI World Congress on. Vol. 4. IEEE, 2009.

[7] G. D. Kuh, J. Kinzie, J. A. Buckley, B. K. Bridges, And J. C. HayeK, What matters to student success: A review of the literature, National Postsecondary Education Cooperative, U.S. Department of Education, Commissioned Report for the National Symposium on PostsecondaryStudent Success: Spearheading a Dialog on Student Success, Tech. Rep.,2006

[8] G. D. Kuh, J. Kinzie, J. H. Schun, And E. J. Whitt,Student Success in College: Creating Conditions That Matter, San Francisco, CA: Jossey- Bass, 2010.

[9] Ahmad Slim, Jarred Kozlick, Gregory L. Heileman, Jeff Wigdahl and Chaouki T. Abdallah, Network Analysis of University Courses, International World Wide Web Conference Committee (IW3C2), WWW14 Companion, April 7-11, 2014, Seoul, Korea. ACM 978-1-4503-2745-9/14/04.

[10] Tushar Ojha, Prediction of Graduation Delay Based on Student Characteristics and Performance, University of New Mexico, UNM Digital Repository, Electrical and Computer Engineering ETDs 2017.

[11] Vincent Tinto, Dropout from higher education: A theoretical synthesis of recent research, Review of Educational Research, $1(45): 89-125,1975$.

[12] George D. Kuh, Jillian Kinzie, John H. Schuh, and Elizabeth J. Whitt. Stu- dent Success in College: Creating Conditions That Matter,Jossey-Bass, San Francisco, CA, 2010.

[13] Ahmad Slim, Jarred Kozlick, Gregory L. Heileman, and Chaouki T.Abdallah, The complexity of university curricula according to course cruciality, In Proceed ings of the 8th International Conference on Complex, Intelligent, and Software Intensive Systems, Birmingham City University, Birmingham, UK, 2014. IEEE.

[14] Ahmad Slim, Jarred Kozlick, Gregory L. Heileman, Jeo Wigdahl, and Chaouki T. Abdallah. Network analysis of university courses. In Proceedings of the 6th Annual Workshop on Simplifying Complex Networks for Practitioners, Seoul, Korea, 2014. ACM. 
[15] Jonathan Kim, The 5 Most Commonly Found Metrics for Student Success, Envisions resources, 2017.

[16] A. T. M. Shakil Ahamed, Navid Tanzeem Mahmood and Rashedur M Rahman, An intelligent system to predict academic performance based on different factors during adolescence, Journal of Information and Telecommunication,(2017) 1:2, 155-175, DOI: $10.1080 / 24751839.2017 .1323488$

[17] RaheelaAsif, Agathe Merceron, Syed AbbasAli and Najmi Ghani- Haider, Analyzing undergraduate students performance using educational data mining, Computers \& Education, Volume 113, October 2017, pp. 177-194.

[18] Ruban, L. M., McCoACh, D. B.,Gender differences in explaining grades using structural equation modelling, Review of Higher Education 284755022005.

[19] Kuncel, N. R., Crede, M., Thomas, L. L., The validity of selfreported grade point averages, class ranks, and test scores: A meta analysis and review of the literature, Review of Educational Research 75163822005.

[20] A. Stim.,Curricular Analytics in Higher Education. PhD thesis, University of New Mexico, 2016

[21] J. Wigdahl, G. L. Heileman, A. Slim, and C. T. Abdallah, Curricular efficiency: What role does it play in student success?, In 2014 ASEE Annual Conference \& Exposition, Indianapolis, Indiana, June 2014. ASEE Conferences.

[22] Daniel James Mundfrom, Estimating course difficulty, IOWA State University, Digital repository, 1991.

Edited by: Rajkumar Rajasekaran

Received: Jul 29, 2018

Accepted: Dec 3, 2018 